\title{
Luxación palmar rotacional de la articulación interfalángica proximal
}

\author{
Rotational palmar dislocation of the proximal \\ interphalangeal finger joint \\ Luis Justino Fernández Palomo, ${ }^{*}$ Juan Manuel Fernández Vázquez, ${ }^{\ddagger}$ \\ Natalia Delia Domínguez Chacón, ${ }^{\ddagger}$ Luis Alfredo Miranda Ocaña ${ }^{\S}$
}

\begin{abstract}
RESUMEN
La luxación palmar rotacional de la articulación interfalángica proximal de los dedos de la mano es una lesión muy rara. La naturaleza de las lesiones de tejidos blandos encontradas clínicamente y las indicaciones para tratarlas de manera cerrada o quirúrgica, así como las técnicas de reconstrucción y los resultados a largo plazo, no han recibido hasta el momento atención, ya que la mayoría de los reportes han sido de casos aislados. Presentamos el caso de una paciente que manifestó tracción y torsión forzada del dedo medio, lo que ocasionó una luxación palmar de la articulación interfalángica proximal del dedo anular. Se realizó reducción cerrada bajo anestesia general y control fluroscópico. También, se realizó maniobra de bostezo radial, la cual fue positiva. Se decidió, por tanto, realizar exploración quirúrgica, encontrando rotura de bandeleta central más rotura del ligamento colateral radial de la articulación interfalángica proximal del dedo medio, las cuales se repararon quirúrgicamente. La paciente actualmente se encuentra con arcos de movilidad funcionales y de vuelta a la actividad física.
\end{abstract}

Palabras clave: Luxación, volar, palmar, interfalángica, dedo.

Nivel de evidencia: IV

\begin{abstract}
Rotational palmar dislocations of the proximal interphalangeal joint of the finger are rare lesions. It consists in a rotational mechanism in almost all of the cases. The nature of the soft tissue lesions found clinically the indications for closed or surgical treatment, reconstruction techniques and long term outcome haven't received attention because most of reports have been isolated cases. We present the case of a patient who presents forced traction and torsion of the middle finger causing palmar dislocation of the proximal interphalangeal joint. Closed reduction is made under general anesthesia and fluoroscopic guidance. Stress maneuvers were done, finding positive radial stress test. Surgical exploration was done finding central slip rupture and radial collateral ligament rupture at the proximal phalanx of middle finger, which were repaired surgically. At present, the patient has functional ranges of movement and back to physical activity.
\end{abstract}

Keywords: Dislocation, volar, palmar, interphalangeal, finger. Level of evidence: $I V$
* Médico adscrito. Especialista en Ortopedia y Traumatología.

‡ Médico adscrito. Especialista en Cirugía de Mano.

$\S$ Médico residente de Ortopedia.

\section{Centro Médico ABC}

Recibido para publicación: 02/01/2020. Aceptado: 03/03/2020.
Correspondencia: Dra. Natalia Delia Chacón Domínguez

Centro Médico ABC Santa Fe, Prolongación Vasco de Quiroga Núm. 4001, Torre Santa Fe Hills. Consultorio 701, Col. Santa Fe, 05348, Alcaldía Cuajimalpa de Morelos, CDMX. Teléfono: (55) 91543107. E-mail: dranataliadmgz@gmail.com

\section{Abreviaturas:}

IFP = Interfalángica proximal.

$\mathrm{LCR}=$ Ligamento colateral radial. 


\section{INTRODUCCIÓN}

La luxación palmar de la articulación interfalángica proximal de los dedos de la mano es una lesión muy rara. Debido a que la mayoría de estas lesiones son reducidas en el sitio del accidente, hasta el momento, la prevalencia no se conoce con certeza. Sin embargo, cuando se produce una luxación rotacional, no es posible la reducción inmediata sin la maniobra específica, además de que la mayoría de estas lesiones requiere tratamiento quirúrgico. El traumatismo que ocasiona esta lesión consiste en un mecanismo rotacional, por una fuerza de compresión longitudinal rotatoria sobre la falange media semiflexionada, que causa ruptura de un ligamento colateral y avulsión parcial de la placa volar al desplazarse la falange
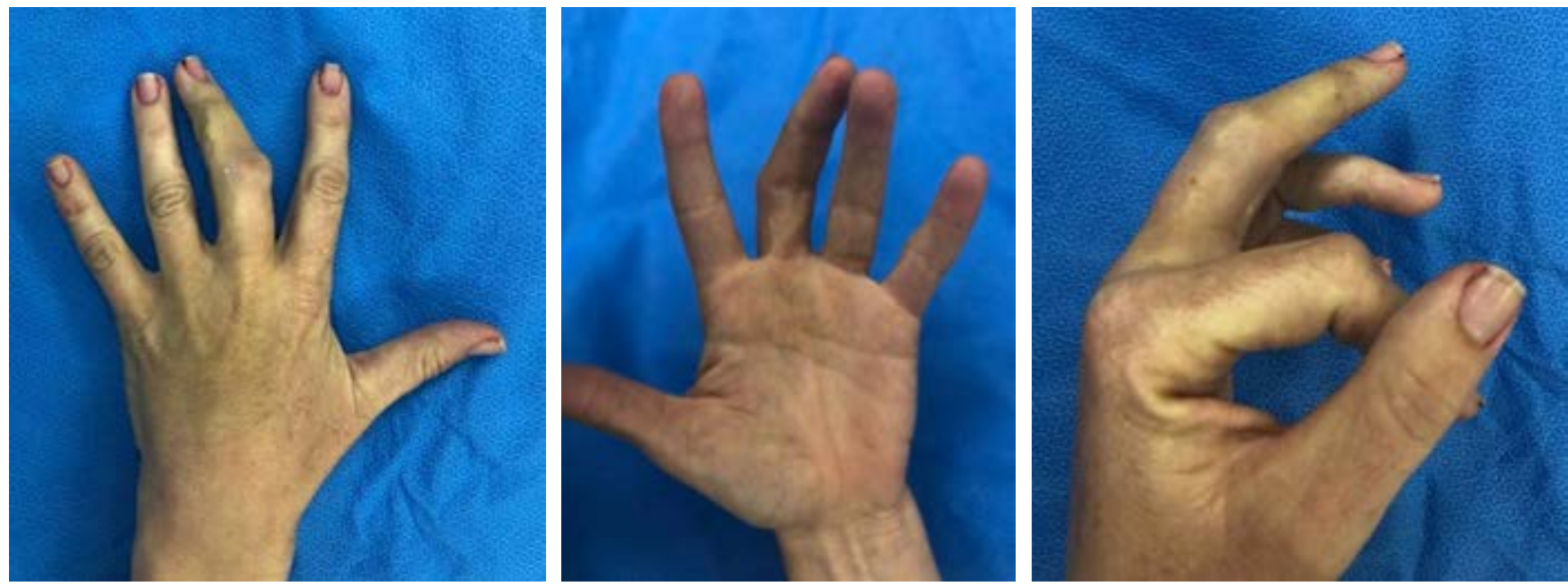

Figura 1: Imágenes clínicas. Vistas dorsal, palmar y lateral de mano izquierda, que muestran la rotación cubital desde la articulación interfalángica proximal del dedo medio.
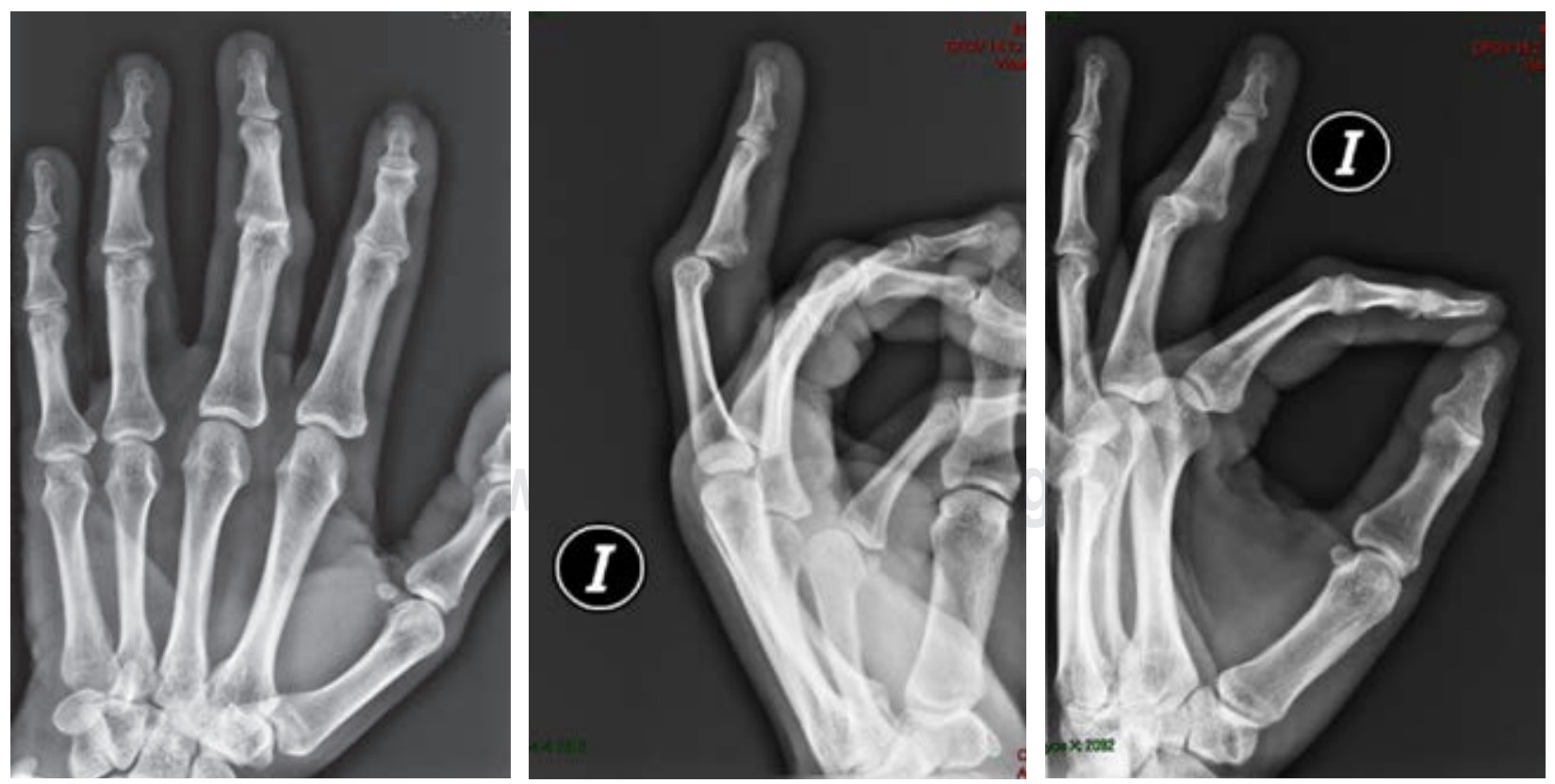

Figura 2: Imágenes radiográficas. Proyección dorso-palmar, lateral y oblicua de la mano izquierda, que muestra luxación palmar interfalángica proximal y rotación cubital. 
media en dirección volar, entonces el cóndilo afectado se desplaza y rompe el mecanismo extensor. ${ }^{1}$

La reducción cerrada debe intentarse siempre de primera intención bajo anestesia local, utilizando para ello el método descrito por Dray y Eaton:1,2 las articulaciones metacarpofalángica e interfalángica proximal son flexionadas, mientras se aplica tracción gentil al dedo junto con movimientos rotatorios para desenganchar la bandeleta lateral atrapada en la articulación interfalángica proximal y, de esta manera, permitir la reducción. Este procedimiento suele lograr la reducción, aunque persiste con inestabilidad, por lo que en la mayoría de casos requiere tratamiento quirúrgico. ${ }^{1}$

En los casos no reducibles e inestables, los estudios demuestran que existe una ruptura longitudinal que separa una de las bandeleta laterales (radial o cubital) de la bandeleta central del tendón extensor; la bandeleta lateral es desplazada hacia la superficie volar de la cabeza de la falange proximal, y parcialmente bloqueada dentro de la articulación interfalángica proximal, con la cabeza de la falange proximal entre la bandeleta central y la bandeleta lateral desplazada. ${ }^{3-6}$

\section{PRESENTACIÓN DEL CASO}

Se trata de mujer de 43 años sin antecedentes de importancia para el padecimiento actual, el cual lo inició al caer desde un caballo al estar practicando equitación, quedando atorado su dedo medio entre las riendas. A la exploración física, presentó dolor intenso, deformidad evidente, aumento de volumen y equimosis con rotación a partir de la articulación interfalángica proximal; el estado neurovascular se mostró distal con hipoestesia y el llenado capilar era normal (Figura 1).

Se le realizaron radiografías en proyección anteroposterior, lateral y oblicua del dedo medio de la mano izquierda, identificando una luxación interfalángica proximal hacia palmar, sin datos de fractura o avulsión ósea y con rotación cubital de la falange media y distal (Figura 2).

Posteriormente, se realizó reducción cerrada de la luxación interfalángica proximal del dedo medio bajo control fluroscópico. Se realizó maniobra de bostezo radial, la cual fue positiva; asimismo, presentó inestabilidad articular, por lo que se decidió realizar exploración quirúrgica y reparación de las lesiones de tejidos blandos.

De esta manera, previa asepsia y antisepsia, con isquemia a $250 \mathrm{mmHg}$, se realizó una incisión dor- so-cubital sobre la articulación interfalángica proximal izquierda; se disecó por planos, encontrando ruptura de la bandeleta central del dedo medio más rotura de ligamento colateral radial a nivel del cóndilo de la falange proximal. Se realizó túnel transverso en porción distal de la falange proximal con broca de $2 \mathrm{~mm}$. Se suturó un extremo del ligamento colateral radial de interfalángica proximal de dedo medio con técnica de sutura transósea con pull-out con Vycril $^{\mathrm{TM}}$ 3-0 y anclada con botón en lado cubital por fuera de la piel. Se reparó intrínsecamente el ligamento colateral radial y la bandeleta central con Nylon 4-0 (Figura 3).
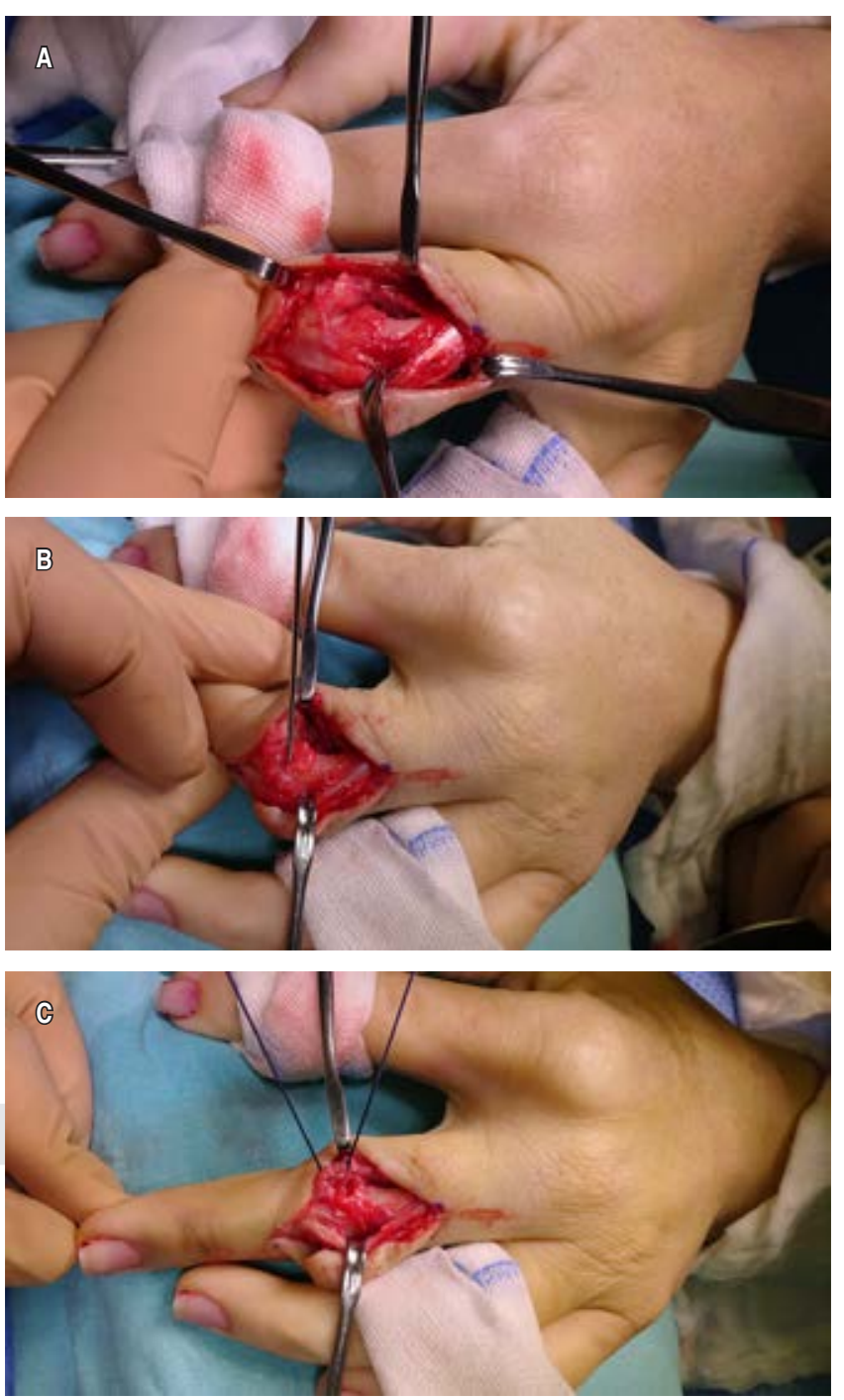

Figura 3: Imágenes transoperatorias. A) Localización de la rotura de la bandeleta lateral y ligamento colateral radial. B y C) Se realizó reparación de ligamento colateral radial con sutura transósea y pull-out con botón. 
Luego del procedimiento quirúrgico, se comprobó la flexión a 100 grados y la extensión a 0 grados de la articulación interfalángica proximal de dedo medio, con estabilidad ligamentaria y articular.

Finalmente, se cubrió la herida con Jelonet y gasas y se colocaron gasas interdigitales. Se colocó férula dorsal de aluminio fijada con Micropore. Se colocó una férula dorsal de Ortho-Glass en posición intrínseco plus y se cubrió con vendaje elástico. Se comprobó el bostezo radial con fluoroscopio, el cual fue negativo en el postoperatorio. Se protegió con esta inmovilización durante tres semanas, después se retiraron los puntos a las dos semanas sin presentar complicaciones, y posterior a tres semanas, se inició flexión pasiva de interfalángica proximal, protegiendo la extensión completa por tres semanas más. Luego de este lapso, se inició el protocolo de rehabilitación durante dos semanas, logrando la flexión y extensión activa completa y sin dolor (Figura 4).

\section{DISCUSIÓN}

Pese a que en el presente caso se pudo realizar la reducción cerrada, al corroborar la ruptura del ligamento colateral radial, se decidió reparar quirúrgicamente para favorecer la estabilidad articular y la recuperación de la paciente. No obstante, debemos tomar en cuenta las causas que pueden hacer imposible la reducción cerrada para poder valorar la reparación de cada una de estas estructuras en caso de ser necesario. Así, cinco causas de irreducibilidad de luxación interfalángica palmar se pueden presentar:

- Interposición de una bandeleta lateral sobre el cóndilo.

- Interposición de la bandeleta central sobre el cóndilo.

- Interposición de ambas: bandeletas central y lateral alrededor del cóndilo.

- Atrapamiento del ligamento colateral roto.

- Atrapamiento de un fragmento osteocondral desplazado.

Johnson y Greene reportaron el primer caso en 1966, en el cual la bandeleta lateral del mecanismo extensor se encontraba interpuesta en la articulación. ${ }^{7}$ Más tarde, en 1974, Murakami reportó dos casos similares en donde la bandeleta central se encontraba interpuesta en la articulación.

La recolocación quirúrgica de la bandeleta lateral desplazada conlleva a una reducción inmediata de la
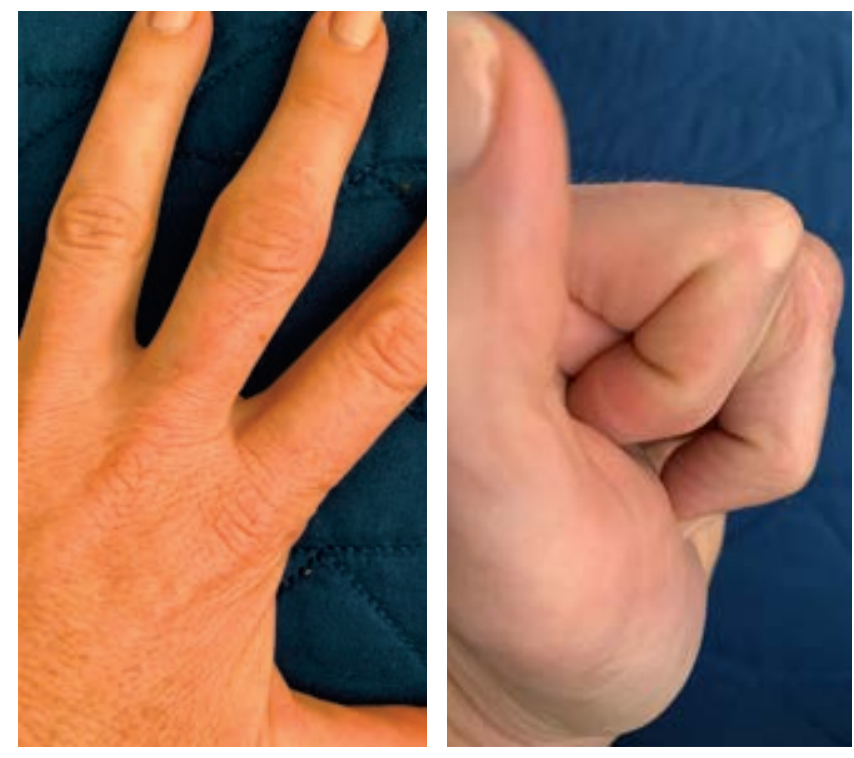

Figura 4: Resultado final con flexión y extensión completa, alineación y estabilidad articular.

articulación luxada. A pesar de que se ha establecido el mecanismo de lesión, así como la naturaleza de las lesiones de tejidos blandos encontradas clínicamente, las indicaciones para tratamiento cerrado o quirúrgico, las técnicas de reconstrucción y los resultados a largo plazo, no han recibido aún atención, ya que la mayoría de los reportes han sido de casos aislados. ${ }^{8}$

\section{CONCLUSIÓN}

Debido a los pocos casos reportados y a que las lesiones de tejidos blandos no siempre suelen presentarse de manera idéntica, el tratamiento debe individualizarse para cada paciente, como en este caso en el que se logró la reducción cerrada; sin embargo, pese a lograr dicha reducción, se encontró inestabilidad de la articulación después del procedimiento, por lo que se decidió reparar quirúrgicamente las estructuras lesionadas, en nuestra paciente, la bandeleta central y el ligamento colateral radial. A las cuatro semanas, se iniciaron con los movimientos pasivos, y a las seis semanas con los movimientos activos, regresando a la actividad física a las 12 semanas. La paciente actualmente se encuentra con arcos de movilidad funcionales y sin dolor residual.

\section{BIBLIOGRAFÍA}

1. Chamseddine A, Jawish R, Zein H. Irreducible volar dislocation of the proximal interphalangeal finger joint. Chirurgie Main. 2009; 28: 255-259. 
2. David P. Green, MD. Green's operative surgery of the hand. 5a. ed. New York USA: Elsevier; 2007.

3. Inoue G, Maeda N Irreducible palmar dislocation of the proximal interphalangeal joint of the finger. J Hand Surg. 1990; 5A: 301-304.

4. Calfee R., Sommerkamp T. Fracture-dislocation about the finger joints. J Hand Surg. 2009; 34A: 1140-1147.

5. Nanno M, Sawaizumi T, Ito H. Irreducible palmar dislocation of the proximal interphalangeal joint of a finger evaluated by magnetic resonance imaging: a case report. J Bone Joint Surg. 2004; 9: 253-256.
6. Posner MA, Wilenski M. Irreducible volar dislocation of the proximal interphalangeal joint of a finger caused by interposition of the intact central slip: a case report. J Bone Joint Surg Am. 1978; 60: 133-134.

7. Johnson FG, Greene MH. Another cause of irreducible dislocation of the proximal interphalangeal joint of a finger. $J$ Bone Joint Surg Am. 1966; 48: 542-544.

8. Peimer C, Sullivan D, Wild D. Palmar dislocation of the proximal interphalangeal joint. J Hand Surg. 1984; 9A: 39-48. 